\title{
Influence of sintering temperature on secondary phases formation and microwave dielectric properties of $\mathrm{Ca}_{2} \mathrm{Ce}_{2} \mathrm{Ti}_{5} \mathrm{O}_{16}$ ceramics
}

\author{
AbDUl MANAN $^{1 *}$, SAMI Ullah KHAN $^{1}$, IBRAHIM QAZI ${ }^{2}$ \\ ${ }^{1}$ Department of Physics, University of Science and Technology Bannu, 28100 KPK, Pakistan \\ ${ }^{2}$ Department of Materials Science and Engineering, Institute of Space Technology, Islamabad 44000, Pakistan
}

\begin{abstract}
$\mathrm{Ca}_{2} \mathrm{Ce}_{2} \mathrm{Ti}_{5} \mathrm{O}_{16}$ dielectric ceramics prepared by conventional solid-state ceramic route was investigated. Phase composition and microwave dielectric properties were measured using XRD and Vector network analyzer, respectively. XRD analysis of the calcined and sintered samples revealed the formation of $\mathrm{CeO}_{2}$ and another unidentified phase (that vanished at $\geqslant 1400{ }^{\circ} \mathrm{C}$ ) as secondary phases along with the parent $\mathrm{Ca}_{2} \mathrm{Ce}_{2} \mathrm{Ti}_{5} \mathrm{O}_{16}$ phase. The amount of the parent $\mathrm{Ca}_{2} \mathrm{Ce}_{2} \mathrm{Ti}_{5} \mathrm{O}_{16}$ phase increased with increasing sintering temperature from $1350{ }^{\circ} \mathrm{C}$ to $1450{ }^{\circ} \mathrm{C}$ accompanied by a decrease in the apparent density. The density decreased but $\varepsilon_{r}$ and $Q_{u} f_{o}$ increased with sintering temperature. An $\varepsilon_{r} \sim 81.5, Q_{u} f_{o} \sim 5915 \mathrm{GHz}$ and $\tau_{f} \sim 219 \mathrm{GHz}$ were achieved for the sample sintered at $1450{ }^{\circ} \mathrm{C}$.
\end{abstract}

Keywords: ceramics; sintering; phase transitions

(C) Wroclaw University of Technology.

\section{Introduction}

Dielectric oxides have revolutionized the microwave wireless communication industry by reducing the size and cost of filter, oscillator and antenna components in applications ranging from cellular phones to global positioning systems. The importance of miniaturization cannot be overemphasized in any hand-held communication application and can be seen in the dramatic decrease in the size and weight of devices such as cell phones in recent years [1].

Ceramics which could function as dielectric resonator must possess three basic properties:

1. High relative permittivity $\left(\varepsilon_{r}\right)$, which insures the reduction in the size of the microwave component because the size of the component is inversely proportional to the square root of the relative permittivity (i.e. $\lambda_{d} \sim D \sim 1 / \sqrt{\varepsilon_{r}}$ ), where $\lambda_{d}$ is the wavelength of the microwaves in the dielectric

*E-mail: drmanan82@yahoo.com media which is equal to the diameter of the dielectric resonator (DR).

2. High unloaded quality factor multiplied by the resonant frequency $\left(Q_{u} f_{o}\right)$, in order to get high signal to noise ratio or selectivity.

3 . near zero temperature coefficient of resonant frequency $\left(\tau_{f}\right)$, to insure temperature stability of the component [2].

Depending on the frequency range of modern communication systems, microwave (MW) dielectrics with varying properties are needed. In the decimeter wave band, high relative permittivity values $(\varepsilon \geqslant 100)$ along with the high thermostability of electro-physical properties and high $Q_{u}$ are required, which enables effective solution of microminiaturization problems. At the present time, solid solutions based on barium-lanthanide titanates $\left(\mathrm{Ba}_{6-x} \mathrm{Ln}_{8+2 x / 3} \mathrm{Ti}_{18} \mathrm{O}_{54}(\mathrm{Ln}=\mathrm{La}-\mathrm{Gd})\right)$, which have a potassium-tungsten bronze structure and $\varepsilon_{r} \approx 80-100$, satisfactorily meet these requirements, but these materials are costly [3]. Therefore, new low cost materials with high permittivity $\left(\varepsilon_{r} \geqslant 100\right)$ and $Q_{u} f_{o}>10,000 \mathrm{GHz}$ with 
$\tau_{f} \sim 0 \mathrm{ppm} /{ }^{\circ} \mathrm{C}$ are essential for further miniaturization of the mobile handsets devices.

In 1994, Bamberger et al. [4] reported the existence of a new $\mathrm{Sr}_{2} \mathrm{Ce}_{2} \mathrm{Ti}_{5} \mathrm{O}_{16}$ compound with a pseudo cubic structure in the $\mathrm{SrO}-\mathrm{CeO}_{2}-\mathrm{TiO}_{2}$ system. Its microwave dielectric properties i.e. $\varepsilon_{r} \sim 113$, high $Q_{u} f_{o} \sim 8000 \mathrm{GHz}$ and $\tau_{f} \sim 306 \mathrm{ppm} /{ }^{\circ} \mathrm{C}$ were reported by Subodh et al. [5]. $\mathrm{Sr}_{2} \mathrm{Ce}_{2} \mathrm{Ti}_{5} \mathrm{O}_{16}$ could be a suitable candidate for further miniaturization of the mobile communication devices provided its high $\tau_{f} \sim 306 \mathrm{ppm} /{ }^{\circ} \mathrm{C}$ is reduced to zero ppm $/{ }^{\circ} \mathrm{C}$ and if its $Q_{u} f_{o}$ could be improved for possible microwave applications. $\mathrm{Ca}$ substitutions for $\mathrm{Sr}$ in other compounds reduced their $\tau_{f}$ with improved $Q_{u} f_{o}$ values [6-8].

The aim of the present study was to investigate the changes in $\tau_{f}$ of $\mathrm{Sr}_{2} \mathrm{Ce}_{2} \mathrm{Ti}_{5} \mathrm{O}_{16}$ through substitutions such as $\mathrm{Ca}$, for possible microwave applications.

\section{Experimental procedures}

The batch composition was fabricated using a solid-state mixed oxide route. $\mathrm{CaCO}_{3}$ (Aldrich, $99+\%), \mathrm{CeO}_{2}$ (Aldrich, $99+\%$ ) and $\mathrm{TiO}_{2}$ (Anatase, Aldrich, $99+\%$ ) were dried at $\approx 200{ }^{\circ} \mathrm{C}$ for $5 \mathrm{~h}$ to remove moisture prior to weighing in order to ensure the correct initial stoichiometry of the compounds. The dried carbonates and oxides were weighed in stoichiometric ratios and wet ballmilled for $4 \mathrm{~h}$ in disposable polyethylene mill jars, using Y-toughened $\mathrm{ZrO}_{2}$ balls as grinding medium and 2-isopropanol as lubricant to make freely flowing slurry. The slurry was dried in an oven at $\approx 95^{\circ} \mathrm{C}$ overnight. The resulting powder was sieved and calcined in air at $1150{ }^{\circ} \mathrm{C}$ for $5 \mathrm{~h}$ at a heating/cooling rate of $5{ }^{\circ} \mathrm{C} / \mathrm{min}$. The calcined powder was ground in a mortar and pestle for $\approx 45 \mathrm{~min}$ to dissociate agglomerates (if any). The powder was pressed into $4 \mathrm{~mm}$ to $5 \mathrm{~mm}$ high and $10 \mathrm{~mm}$ diameter pellets at $150 \mathrm{MPa}$. The green pellets were placed on platinum foils and sintered in air at $1350{ }^{\circ} \mathrm{C}$ to $1450{ }^{\circ} \mathrm{C}$ for $4 \mathrm{~h}$ at a heating/cooling rate of $5{ }^{\circ} \mathrm{C} / \mathrm{min}$. Phase analysis of the calcined and sintered crushed pellets was carried out using a Philips X-ray diffractometer operating at $30 \mathrm{kV}$ and $40 \mathrm{~mA}$ at a scan speed of $1 \% \mathrm{~min}$ for $2 \theta=$ $10^{\circ}-70^{\circ}$ with a step size of $0.02^{\circ}$. Bulk densities of the sintered pellets were measured using the Archimedes method.

Microwave dielectric properties were measured using a R3767CH Agilent network analyzer using cavity method. The cylindrical pellets were placed on a low loss quartz single crystal in the center of an Au-coated brass cavity away from the walls of the cavity. $\tau_{f}$ was measured by noting the temperature variation of the $\mathrm{TE}_{01 \delta}$ resonance at temperatures ranging from $20{ }^{\circ} \mathrm{C}$ to $80{ }^{\circ} \mathrm{C}$ using equation (1):

$$
\tau_{f}=\left(f_{2}-f_{1}\right) / f_{1} \Delta T
$$

where $f_{1}$ and $f_{2}$ are the resonant frequencies at $20{ }^{\circ} \mathrm{C}$ and $80{ }^{\circ} \mathrm{C}$ respectively, and $\Delta T$ is the difference between the initial and final temperature.

\section{Result and discussion}

\subsection{Phase analysis}

Fig. 1 shows the XRD patterns recorded for the calcined and sintered samples. The XRD pattern of the calcined sample shows the formation of $\mathrm{CeO}_{2}$ as the major phase with the peaks indexed according to PDF\#34-394 and $\mathrm{Ca}_{2} \mathrm{Ce}_{2} \mathrm{Ti}_{5} \mathrm{O}_{16}$ and an unidentified phase as minor phases respectively. The peaks of the parent $\mathrm{Ca}_{2} \mathrm{Ce}_{2} \mathrm{Ti}_{5} \mathrm{O}_{16}$ phase were indexed according to PDF\#49-1554 for $\mathrm{Sr}_{2} \mathrm{Ce}_{2} \mathrm{Ti}_{5} \mathrm{O}_{16}$ having cubic structure with the peaks position shifted towards higher diffraction angles i.e. smaller d values due to smaller ionic radius of $\mathrm{Ca}^{+2}(1.34 \AA)$ than $\mathrm{Sr}^{+2}$ (1.44 $\AA$ ) [9]. At temperatures $\geqslant 1350{ }^{\circ} \mathrm{C}$, the parent $\mathrm{Ca}_{2} \mathrm{Ce}_{2} \mathrm{Ti}_{5} \mathrm{O}_{16}$ phase was developed as the major phase accompanied by a decrease in the unidentified as well as $\mathrm{CeO}_{2}$ phases. The unidentified phase completely vanished at $\geqslant 1400{ }^{\circ} \mathrm{C}$ as shown in Fig. 1 . The lattice parameter calculated from the XRD data is $\mathrm{a}=3.8511 \AA$ and unit cell volume is $\mathrm{V}=57.11 \AA^{3}$.

\subsection{Microwave dielectric properties}

Fig. 2 shows the experimental density $\left(\rho_{\text {exp }}\right)$ and relative permittivity $\left(\varepsilon_{r}\right)$ of the sintered $\mathrm{Ca}_{2} \mathrm{Ce}_{2} \mathrm{Ti}_{5} \mathrm{O}_{16}$ ceramics with increasing sintering temperature. Generally, the trend in the variation 


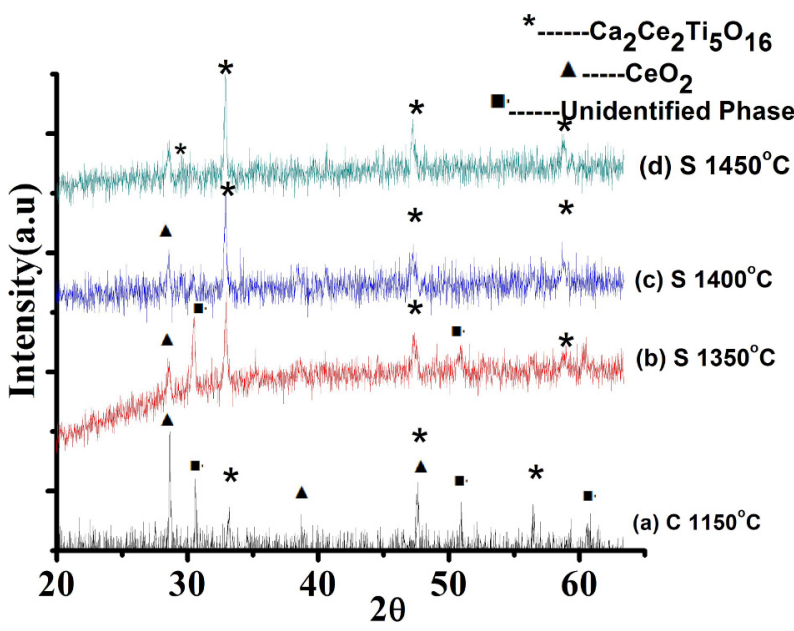

Fig. 1. XRD patterns from (a) calcined and (b) - (d) sintered samples of $\mathrm{Ca}_{2} \mathrm{Ce}_{2} \mathrm{Ti}_{5} \mathrm{O}_{16}$ ceramics, showing the formation of secondary phases along with the parent $\mathrm{Ca}_{2} \mathrm{Ce}_{2} \mathrm{Ti}_{5} \mathrm{O}_{16}$ phase.

of $\varepsilon_{r}$ with sintering temperature follows density, but the trend does not hold in the present study. The bulk density decreases while $\varepsilon_{r}$ increases with increasing sintering temperature from $1350{ }^{\circ} \mathrm{C}$ to $1450{ }^{\circ} \mathrm{C}$. This contradiction is due to the existence of the $\mathrm{CeO}_{2}$ and unidentified secondary phase, which disappeared at temperature $\geqslant 1400{ }^{\circ} \mathrm{C}$, but might have lower $\varepsilon_{r}$ and higher apparent density than the parent $\mathrm{Ca}_{2} \mathrm{Ce}_{2} \mathrm{Ti}_{5} \mathrm{O}_{16}$ phase as observed in XRD pattern (Fig. 1). In the present study, the highest $\left(\varepsilon_{r(\exp )}\right) \sim 81$ was achieved at $1450{ }^{\circ} \mathrm{C}$. The experimental dielectric constants $\left(\varepsilon_{r(\text { exp })}\right)$ were corrected for porosity using Rushman and Strivens equation [10] and the highest was to be 87.2 at $1450{ }^{\circ} \mathrm{C}$. The $\mathrm{Ca}$ substitution for $\mathrm{Sr}$ in $\mathrm{Sr}_{2} \mathrm{Ce}_{2} \mathrm{Ti}_{5} \mathrm{O}_{16}$ ceramics lowers its $\varepsilon_{r}$ from 113 to 81.5 due to lower ionic dielectric polarizability of $\mathrm{Ca}\left(3.14 \AA^{3}\right)$ than $\mathrm{Sr}\left(4.24 \AA^{3}\right)$ in the present study [11]. The observed and corrected values of $\varepsilon_{r}$ are also summarized in Table 1.

The $Q_{u} f_{o}$ of the $\mathrm{Ca}_{2} \mathrm{Ce}_{2} \mathrm{Ti}_{5} \mathrm{O}_{16}$ ceramics sintered at $1350{ }^{\circ} \mathrm{C}$ to $1450{ }^{\circ} \mathrm{C}$ is shown in Fig. 3 and also summarized in Table 1 . There are various factors that affect the dielectric losses or its inverse $\left(Q_{u} f_{o}\right)$ in the microwave region. These include defects such as porosity, grain boundaries, microcracks and secondary phase(s). The $Q_{u} f_{o}$ increased with increasing sintering temperature, showing opposite trend to experimental density $\left(\rho_{\text {exp }}\right)$. The increase in $Q_{u} f_{o}$ might be due to the vanishing of the unidentified phase at $\geqslant 1400{ }^{\circ} \mathrm{C}$ and a decrease in the $\mathrm{CeO}_{2}$ phase as well as an increase in the parent $\mathrm{Ca}_{2} \mathrm{Ce}_{2} \mathrm{Ti}_{5} \mathrm{O}_{16}$ phase (Fig. 1). The temperature coefficient of resonant frequency $\left(\tau_{f}\right)$ increased from $172 \mathrm{ppm} /{ }^{\circ} \mathrm{C}$ to $219 \mathrm{ppm} /{ }^{\circ} \mathrm{C}$ with increasing sintering temperature from $1350{ }^{\circ} \mathrm{C}$ to $1450{ }^{\circ} \mathrm{C}$. This indicated that the unknown phase had lower $\tau_{f}$ than the parent $\mathrm{Ca}_{2} \mathrm{Ce}_{2} \mathrm{Ti}_{5} \mathrm{O}_{16}$ phase.

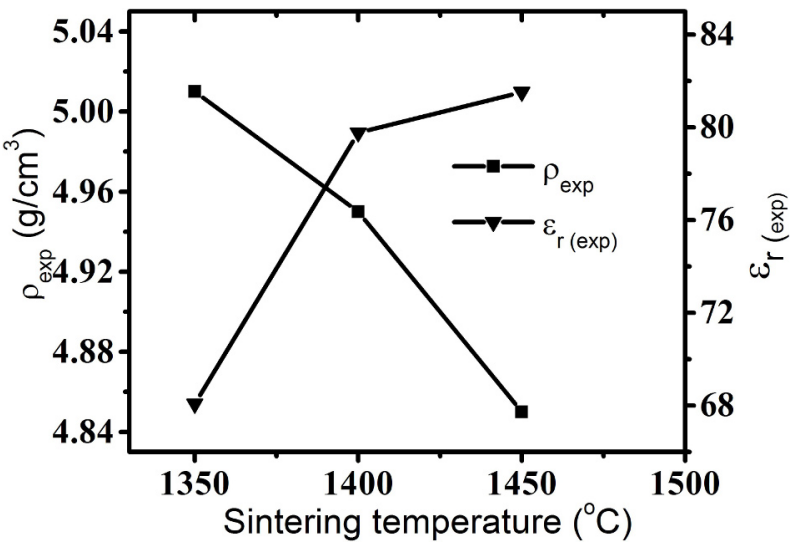

Fig. 2. Variation in $\rho_{\text {exp }}$ and $\varepsilon_{r}$ of $\mathrm{Ca}_{2} \mathrm{Ce}_{2} \mathrm{Ti}_{5} \mathrm{O}_{16}$ ceramics as a function of sintering temperature.

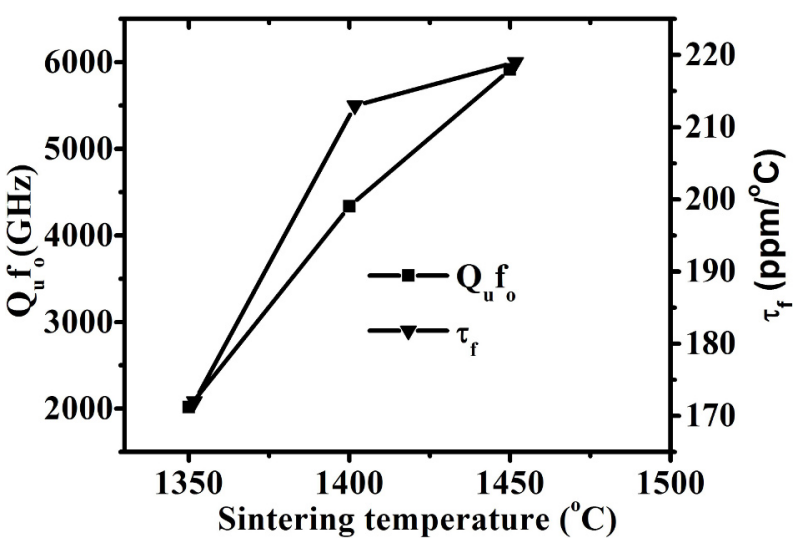

Fig. 3. Variation in $Q_{u} f_{o}$ and $\tau_{f}$ of $\mathrm{Ca}_{2} \mathrm{Ce}_{2} \mathrm{Ti}_{5} \mathrm{O}_{16}$ ceramics as a function of sintering temperature.

\section{Conclusion}

The density decreased but $\varepsilon_{r}$ and $Q_{u} f_{o}$ increased with sintering temperature probably due to 
Table 1. Preparation conditions, observed density and microwave dielectric properties of $\mathrm{Ca}_{2} \mathrm{Ce}_{2} \mathrm{Ti}_{5} \mathrm{O}_{16}$ ceramics.

\begin{tabular}{ccccccc}
\hline $\begin{array}{c}\mathrm{ST} \\
\left({ }^{\circ} \mathrm{C}\right)\end{array}$ & $\begin{array}{c}\rho_{\exp } \\
\left(\mathrm{g} / \mathrm{cm}^{3}\right)\end{array}$ & $\begin{array}{c}\varepsilon_{r} \\
(\text { experimental})\end{array}$ & $\begin{array}{c}\varepsilon_{r} \\
(\text { corrected })\end{array}$ & $\begin{array}{c}Q_{u} f_{o} \\
(\mathrm{GHz})\end{array}$ & $\tan \delta$ & $\begin{array}{c}\tau_{f} \\
\left(\mathrm{ppm} /{ }^{\circ} \mathrm{C}\right)\end{array}$ \\
\hline \hline 1350 & 5.01 & 68.07 & 72.8 & 2017 & 0.00049579 & 172 \\
1400 & 4.95 & 79.77 & 85.4 & 4337 & 0.00023057 & 213 \\
1450 & 4.85 & 81.52 & 87.2 & 5915 & 0.00016906 & 219 \\
\hline
\end{tabular}

the presence of $\mathrm{CeO}_{2}$ and unidentified phases. An $\varepsilon_{r} \sim 81.5, Q_{u} f_{o} \sim 5915 \mathrm{GHz}$ and $\tau_{f} \sim 219 \mathrm{GHz}$ were achieved for the sample sintered at $1450{ }^{\circ} \mathrm{C}$. Further work is in progress to tune the $\tau_{f}$ to zero for possible application.

\section{Acknowledgements}

The authors acknowledge the financial support of the Higher Education Commission of Pakistan under the Interim Placement Fresh PhD program (IPFP) Scheme and Mr. Simon Nicholls at the Department of Materials Science and Engineering University of Sheffield UK for the measurement of microwave dielectric properties.

\section{References}

[1] Sebastian M.T., Dielectric Materials for Wireless Communication, $1^{\text {st }}$ Ed., Elsevier Science \& Technology, GB, 2008.

[2] Freer R., Azough F., J. Eur. Ceram. Soc., 28 (2008), 1433.
[3] Belous A., Ovchar O., Acta Phys. Pol. A, 117 (2010), 221.

[4] Bamberger C.E., Haverlock T.J., Kopp O.C., $J$. Am. Ceram. Soc., 77 (1994), 1659.

[5] Subodh G., Sebastian M.T., Mater. Sci. Eng B-Adv., 136 (2007), 50.

[6] Manan A., IQbal Y., Qazi I., J. Mater. Sci., 46 (2011), 3415.

[7] IQbal Y., Manan A., Reaney I.M., Mater. Res. Bull., 46 (2011), 1092.

[8] Bijumon P.V., Sebastian M.T., Dias A., Moreira R.L., Mohanan P., J. Appl. Phys., 97 (2005). 104108.

[9] Shannon R.D., Acta Crystallogr. A, 32 (1976), 751.

[10] Rushman D.F., Strivens M.A., P. Phys. Soc., 59 (1947), 1011.

[11] Shannon R.D., J. Appl. Phys., 73 (1993), 348. 